\title{
PENGARUH PERUBAHAN HARGA LADA PUTIH TERHADAP KESEJAHTERAAN MASYARAKAT DI KECAMATAN JEBUS KABUPATEN BANGKA BARAT
}

\section{THE EFFECT OF THE CHANGE OF WHITE PEPPER PRICES ON COMMUNITY WELFARE IN JEBUS DISTRICT, WEST BANGKA REGENCY}

\author{
Ilham Nurllah*, Jaya Iswari \\ Program Studi Manajemen, Fakultas Ekonomi, Universitas Bangka Belitung \\ *Email: Ilhamnurllah@gmail.com
}

(Diterima 21-05-2019; Disetujui 20-07-2019)

\begin{abstract}
ABSTRAK
Lada putih atau merica (piper nigrum L.) merupakan tanaman rempah-rempah dari komoditas perkebunan khas Bangka Belitung, salah satunya yang dikembangkan di Kecamatan Jebus Kabupaten Bangka Barat yang dianggap sebagai perkebunan rakyat oleh petani. Penurunan harga lada putih yang cukup drastis di tingkat petani menjadi persoalan sosial dalam bidang ekonomi yang berimplikasi kepada persoalan penurunan produktivitas. Ditambah karakteristik dari petani lada ini rata-rata hanya memiliki tingkat pendidikan yang sangat rendah, serta pengetahuan bercocok tanamnya yang hanya didapatkan dari hasil pengalaman turun-temurun. Metode penelitian yang digunakan yaitu metode kualitatif (naturalistik) bersifat natural dengan melakukan wawancara langsung terhadap objek yang diteliti. Analisis ini merupakan interprestasi data serta pengolahan data yang sudah dilaksanakan dengan memberi keterangan dan penjelasan dari objek tersebut. Hasil penelitian menunjukan bahwa sistem penanaman, sistem perawatan dan sistem sosial ekonomi petani yang tidak seimbang dengan sistem produksi dan produktivitas. Tingkat signifikasi tentang perbedaan tersebut secara signifikan menunjukan kurangnya kesejahteraan ekonomi masyarakat khususnya petani lada. Oleh sebab itu, rekayasa sosial (kelembagan) tentang lemahnya persaingan lada di pasar dunia tidak hanya berdampak kepada devisa negara, tetapi juga sangat berdampak kepada para petani khususnya di Kecamatan Jebus ini yang sudah banyak beralih profesi.
\end{abstract}

Kata kunci: Petani, Lada, Dampak

\section{ABSTRACT}

White pepper or pepper (piper nigrum L.) is a spice plant from plantation commodities typical of Bangka Belitung, one of which is developed in Jebus District, West Bangka Regency which is considered a smallholder plantation by farmers. The dramatic decline in the price of white pepper at the farm level has become a social problem in the economic field which has implications for the problem of decreasing productivity. Plus the characteristics of these pepper farmers only have very low education levels, and their farming knowledge is only obtained from the results of hereditary experiences. The research method used is a qualitative (naturalistic) method that is natural by conducting direct interviews with the object under study. This analysis is the interpretation of data and data processing that has been carried out by giving information and explanation of the object. The results of the study show that the planting system, care system and socio-economic system of farmers are not balanced with the production system and productivity. Significant level of these differences significantly indicates a lack of economic welfare of the community, especially pepper farmers. Therefore social engineering (institutionalization) about the weakness of pepper competition in the world market not only has an impact on foreign exchange, but also greatly affects the farmers, especially in Jebus Subdistrict who have switched professions.

Keywords: Farmers, Pepper, Impact 


\section{PENGARUH PERUBAHAN HARGA LADA PUTIH TERHADAP KESEJAHTERAAN \\ MASYARAKAT DI KECAMATAN JEBUS KABUPATEN BANGKA BARAT \\ Ilham Nurllah, Jaya Iswari}

PENDAHULUAN

Lada putih atau merica (piper nigrum L.) merupakan salah satu tanaman rempah-rempah yang biasanya digunakan sebagai penyedap rasa makanan, biji lada biasanya juga digunakan sebagai obat herbal dan anti bakteri. Lada juga banyak diminati oleh bangsa-bangsa di Eropa, kebutuhan lada di dunia mencapai angka 350.000 ton/tahun. Kontribusi Indonesia sebagai pengekspor lada mencapai $29 \%$ dari kebutuhan dunia, terbesar kedua setelah Vietnam. Produksi lada tahun 2014 mencapai 91.941 ton (Direktorat Jenderal Perkebunan, 2014).

Bangka Belitung merupakan salah satu daerah penghasil lada putih terbaik di Indonesia, lada juga menjadi komoditif utama di Bangka Belitung selain biji timah, karena sebagian besar masyarakat di Bangka Belitung memiliki perkebunan lada atau lebih dikenal dengan nama sahang di masyarakat pulau Bangka. Aktivitas petani selama melakukan budidaya tanaman lada adalah mengharapkan produktivitas yang tinggi. Produktivitas adalah kemampuan menghasilkan produk dalam luasan dan periode waktu tertentu. Produktivitas tidak dapat dipisahkan dengan pengertian produksi karena keduanya saling berhubungan. Apabila terdapat permasalahan produktivitas maka produksi selalu tersangkut didalamnya. Akan tetapi dalam melakukan kegiatan budidaya tanaman lada ini sering mengalami beberapa faktor yang justru mempengaruhi produktivitas dan produksi menjadi lebih rendah dikarenakan satuan harga per $\mathrm{kg}$ yang tidak sebanding dengan modal yang dikeluarkan selama proses penanaman hingga masa panen berlangsung.

Dipandang dari sudut efisiensi, semakin luas lahan yang akan diusahakan maka semakin tinggi hasil dan pendapatan per satuan luasnya (Suratiyah, 2015). Dalam usaha budidaya tanaman, lahan pertanian adalah tanah yang disiapkan untuk diusahakan sebagai usahatani yang diukur dalam satuan hektar. Pada tanaman lada, luas panen dihitung pada saat tanaman lada telah berumur 3 tahun setelah tanam lada. Tanaman yang dikategorikan panen merupakan tanaman yang sudah membuahkan hasil paling sedikit $11 \%$ dari keadaan normal yang mungkin disebabkan oleh cuaca, hama ataupun penyakit yang menyerang tanaman lada tersebut. Jumlah luas panen mempengaruhi hasil yang didapatkan. Ketika luas panen menurun, maka 
produtivitas lada juga akan menurun; begitu pula sebaliknya. Contohnya, produksi lada di Bangka Belitung tahun 2015 (31.048 ton), tahun 2016 (31.896 ton) dan tahun 2017 (32.352 ton). Produktivitasnya tahun $2015 \quad(1.259$ kg/ha), 2016 (1.277 kg/ha), dan 2017 $(1.282 \mathrm{~kg} / \mathrm{ha}) \quad$ (Direktorat Jenderal Perkebunan 2015). Data ini menunjukkan bahwa semakin tinggi produktivitas, maka semakin tinggi pula produksi yang dihasilkan, dan setiap tahun produksi lada di Bangka Belitung semakin meningkat.

Perawatan merupakan suatu kegiatan yang terprogram, dalam proses perawatan tanaman lada yang harus diperhatikan ialah pemupukan dan pemberian pestisida yang tepat tepat terhadap tanaman lada. Pemupukan pada tanaman lada sangat berpengaruh terhadap produktivitas lada. Pupuk yang diberikan pada tanaman lada ada dua jenis, yaitu pupuk organik dan pupuk anorganik. Pupuk organik adalah pupuk yang paling bagus untuk tanaman lada, karena pupuk organik akan membuat tanaman lada bertahan hidup lebih lama dan tahan terhadap penyakit serta akan berbuah lebat. Biasanya pemupukan dilakukan saat awal musim hujan dan akhir musim hujan agar pupuk lebih cepat diserap oleh tanah dan tanaman.
Berikutnya pemberian pestisida yang tepat untuk tanaman lada yang bertujuan untuk membasmi hama pada tanaman lada agar tanaman lada dapat terhindar dari berbagai penyakit seperti penyakit kuning, busuk pangkal dan penyakit keriting. Dengan demikian, para petani dapat meningkatkan produksi dan produktivitasnya sehingga dapat mengungguli dua elemen utama konsepsi keunggulan bersaing menurut Walker (2009) di pasar internasional, yaitu (1) memposisikan lini produk yang lebih efektif dibandingkan pesaing, dan (2) mempertahankan posisi sumber daya pasar dalam melawan pesaing.

Banyak kendala yang dialami oleh masyarakat dalam berkebun lada, antara lain kendala hama dan cuaca serta harga pupuk yang mahal. Semua kendalakendala tersebut sangat berpengaruh terhadap hasil produksi, terutama kendala harga pupuk yang mahal. Meskipun ada pupuk yang bersubsidi tetapi itu tetap membebani mayarakat karena harga jual dari lada putih sekarang berkisar antara $\mathrm{Rp}$ 46.000-55.000/kg, tidak sebanding dengan modal yang dikeluarkan oleh petani dari penanaman, perawatan, hingga proses penjemurannya.

Lada merupakan tanaman yang memiliki jangka waktu panen yang cukup 


\section{PENGARUH PERUBAHAN HARGA LADA PUTIH TERHADAP KESEJAHTERAAN \\ MASYARAKAT DI KECAMATAN JEBUS KABUPATEN BANGKA BARAT \\ Ilham Nurllah, Jaya Iswari}

lama, butuh waktu 3 tahun dari awal penanaman hingga masa panennya, setelah itu lada bisa dipanen 1 tahun sekali, serta usia dari tanaman lada itu sendiri hanya bisa bertahan sekitar 6-7 tahun tergantung dari perawatannya. Produksi lada di Bangka Belitung tahun 2015 (31,048 ton), tahun 2016 (31.896 ton) dan tahun 2017 (32.352 ton), dan produktivitasnya tahun $2015 \quad(1.259$ $\mathrm{kg} / \mathrm{ha})$, tahun 2016 (1.277 kg/ha), tahun 2017 (1.282 kg/ha) (Direktorat Jenderal Perkebunan, 2015), ini menandakan bahwa semakin tinggi produktivitas maka semakin tinggi pula produksi yang dihasilkan, dan setiap tahun produksi lada di Bangka Belitung semakin meningkat.

\section{METODE PENELITIAN}

Penelitian yang digunakan pada penelitian ini adalah penelitian kualitatif. Metode penelitian kualitatif disebut juga penelitian naturalistik, disebut naturalistik karena situasi lapangan penelitian bersifat natural atau sebagaimana adanya tanpa adanya rekayasa, diatur dengan eksperimen atau wawancara langsung terhadap objek yang diteliti. Penggunaan pendekatan kualitatif karena penelitian ini merupakan studi kasus yang banyak variabel yang harus diperhatikan untuk mendapatkan gambaran dan keterangan-keterangan mengenai objek yang diteliti.

Penentuan lokasi dilakukan secara sengaja dengan pertimbangan banyaknya keluhan dari masyarakat Kecamatan Jebus terhadap menurunnya harga lada setiap tahun. Penentuan informan dilakukan secara random yaitu pada masyarakat-masyarakat yang ada di Kecamatan Jebus, Kabupaten Bangka Barat, Provinsi Kepulauan Bangka Belitung. Jumlah sampel dalam penelitian ini sebanyak 20 petani.

Validasi dalam penelitian kualitaif ini berbeda dengan metode penelitian lainnya karena terdapat beberapa langkah yang digunakan untuk memastikan akurasi dari hasil yang diperoleh dalam penelitian ini (Creswell, 2005), diantaranya:

- Triangulasi sumber data yang berbeda dengan memeriksa berbagai kejadian yang membangun kepada suatu koherensi.

- Klarifikasi hasil temuan dengan berbagai studi yang dilakukan dan data yang tersedia.

- Memunculkan informasi yang tidak sesuai untuk mengimbangi informasi yang diperoleh, diskusikan informasi yang bertolak belakang berdasarkan kredibilitas sumber informasi. 
- Berada di lapangan untuk waktu yang lama untuk memperoleh pemahaman yang mendalam atas fenomena yang terjadi dan menentukan kredibilitas dari narasumber (informan) yang sebenarnya.

- Menggunakan narasumber ahli dari eksternal untuk memperoleh sebelum menarik suatu kesimpulan.

Jenis data yang digunakan dalam penelitian ini adalah data primer yang diperoleh melalui wawancara langsung terhadap narasumber menggunakan kuesioner. Penggunaan data primer ini bertujuan untuk mempermudah dalam mengetahui keadaan ekonomi dan kesejahteraan masyarakat yang ada di Kecamatan Jebus Kabupaetn Bangka Barat.

\section{HASIL DAN PEMBAHASAN}

Keadaan Umum Lokasi Penelitian

Kecamatan Jebus Kabupaten Bangka Barat Provinsi Bangka Belitung memiliki 12 desa yang rata-rata masyarakatnya memiliki usaha perkebunan lada.

\section{Karateristik Petani Lada}

Umur

Berdasarkan kelompok umur produktif (18-64 tahun), maka dapat diketahui bahwa sebagian besar petani termasuk ke dalam usia produktif, dimana rata-rata usianya adalah 40 tahun, dengan usia termuda 20 tahun dan usia tertua 60 tahun. Dapat disimpulkan bahwa masyarakat yang memiliki usahatani lada berumur di atas 18 tahun.

\section{Pendidikan}

Tingkat pendidikan petani di Kecamatan Jebus masih tergolong rendah, hal ini ditunjukan dengan banyaknya informan yang memiliki pendidikan terakhir SD sebanyak 10 orang $(50 \%)$, pendidikan terakhir SMP sebanyak 6 orang $(30 \%)$, dan sisanya pendidikan terakhir SMA sebanyak 4 orang (20\%). Ini menandakan bahwa petani lada di Kecamatan Jebus kurang menerima pendidikan. Seharusnya semakin tinggi pendidikan maka semakin luas pemikiran dan pengetahuan para petani terhadap budidaya tanaman lada, dan para petani lebih berpeluang untuk mendapatkan penghasilan yang lebih besar untuk memenuhi kebutuhannyaa sehari-hari.

\section{Luas Lahan}

Dari hasil penelitian diketahui bahwa petani memiliki luas lahan yang bervariasi yaitu dari 0,5-1 hektar, luas lahan yang mendominasi seluas 1 hektar, yaitu sebanyak 15 orang (75\%), dan 


\section{PENGARUH PERUBAHAN HARGA LADA PUTIH TERHADAP KESEJAHTERAAN \\ MASYARAKAT DI KECAMATAN JEBUS KABUPATEN BANGKA BARAT \\ Ilham Nurllah, Jaya Iswari}

sisanya memiliki luas lahan di atas 0,5 hektar dan di bawah 1 hektar sebanyak 5 orang $(25 \%)$.

\section{Pengalaman berusahatani}

Dalam bidang pertanian jika pengalaman petani dalam bertani diperoleh sejak ia kecil, maka pengalaman dan pengetahuan bertaninya akan semakin baik. Semakin tua atau semakin lama petani melakukan usahataninya, maka petani juga akan semakin matang sehingga semakin banyak pula pengalaman dan pengetahuannya (Suprayogo, 2007).

Dalam penelitian ini umumnya para petani lada memiliki pengalaman ratarata 10 tahun dalam berusahatani, hal ini menunjukan bahwa para petani sudah cukup matang dan berpengalaman dalam berusahatani lada. Kondisi ini mencakup aktivitas ekonomi dan aktivitas sosial yang dilengkapi dengan berbagai artefak teknis atau teknologi. Aktivitas-aktivitas yang dilakukan oleh manusia sebagai agen, baik sosial, ekonomi maupun teknologi dalam jangka pendek maupun jangka panjang memilik dampak terhadap lingkungan (Folke, 2006).

\section{Pengetahuan petani terhadap perubahan harga lada putih}

Menurut Mauludi dan Yuhono (1996), ada tiga sistem dalam tata niaga lada, yaitu: pertama petani menjual ke pedagang/pengumpul desa, lalu ke pedagang di kecamatan, kemudian ke pedagang kabupaten dan terakhir ke eksportir. Pada saluran ini biasanya lada yang dijual petani dalam jumlah kecil (10 kg). Kedua, saluran tataniaga yang kadang-kadang dilakukan yakni apabila lada hitam yang dijual petani dalam jumlah cukup banyak (puluhan $\mathrm{kg}$ ). Salurannya adalah dari petani langsung ke pedagang kecamatan lalu ke pedagang di kabupaten dan terakhir ke eskportir. Ketiga, sistem yang sekali-kali dilakukan yakni apabila petani menjual lada dalam jumlah banyak (100 kg atau lebih). Petani akan menjual langsung ke pedagang kabupaten, lalu dari pedagang kabupaten dijual kembali ke eksportir.

Hasil penelitian menunjukkan bahwa semua petani mengetahui adanya harga lada putih yang tidak stabil. Oleh karena itu, sebanyak 10 orang petani $(50 \%)$ petani lebih memilih untuk menyimpan hasil panennya dari pada langsung menjualnya, sedangkan 6 orang petani lainnya (30\%) memilih untuk menjual setengah hasil panennya untuk modal dan menyimpan setengahnya lagi untuk tabungan masa depan atau menunggu harga lada tinggi kembali, dan 4 orang petani (20\%) lainnya lebih memlih untuk menjual semua hasil 
panennya untuk mencukupi kehidupan sehari-hari dan untuk menambah modal membeli pupuk.

Menurut Saefudin (1999), sistem produksi harus sesuai dengan sistem saluran pemasaran, karena dalam setiap prosesnya pemasaran mempunyai saluran pemasaran yang berbeda satu sama lain yang tergantung pada keadaan daerah, waktu dan kemajuan teknologi. Selain itu, dalam pengelolaan produktivitasnya, petani harus menguasai salah satu fungsi yang paling utama yaitu manajemen pemasaran. Manajemen pemasaran adalah kegiatan penganalisisan, perencanaan, pelaksanaan, dan pengendalian program-program yang dibuat untuk membentuk, membangun, dan memelihara, keuntungan dari pertukaran melalu sasaran pasar guna mencapai tujuan dalam jangka panjang (Kotler dan Keller, 2012).

\section{Dampak Perubahan Harga Lada Terhadap Perekonomian}

Pada tahun 2004, produksi lada Indonesia mencapai 94.371 ton (Direktorat Jenderal Bina Produksi Perkebunan 2006) atau menduduki urutan kedua dunia setelah Vietnam dengan produksi 105.000 ton (Asosiasi Eksportir ada Indonesia 2004; International Pepper Community 2004). Luas areal dan produksi lada selama tahun 2000-2005 cenderung meningkat, yaitu dari 150.531 ha pada tahun 2000 menjadi 211.729 ha pada tahun 2005, serta hasil produksi skala besarnya yaitu dari produksi 69.087 ton pada tahun 2000 menjadi 99.1 39 ton pada tahun 2005

(Direktorat Jenderal Bina Produksi Perkebunan 2006). Namun, ekspor cenderung menurun rata-rata 9,60\%/tahun (Direktorat Jenderal Bina Produksi Perkebunan, 2006). Total ekspor lada dari negara-negara produsen pada tahun 2004 mencapai 230.625 ton. Dari total ekspor tersebut, Indonesia mengekspor 45.760 ton atau sekitar 19,80\%. Dilihat dari volume ekspor, masih terbuka peluang yang besar bagilndonesia untuk meningkatkan ekspor lada. Devisa negara dari ekspor lada sekitar US\$ 49,566 juta (International Pepper Community, 2005). Di pasar internasional, lada Indonesia mempunyai kekuatan dan daya jual tersendiri karena cita rasanya yang khas. Lada Indonesia dikenal dengan nama Muntok white pepper untuk lada putih dan Lampong black pepper untuk lada hitam (Yuhono 2005). Sebagian besar (99\%) pertanaman lada diusahakan dalam bentuk perkebunan.

Persoalan lada putih yang paling menonjol pada tahun 2018/2019 


\section{PENGARUH PERUBAHAN HARGA LADA PUTIH TERHADAP KESEJAHTERAAN \\ MASYARAKAT DI KECAMATAN JEBUS KABUPATEN BANGKA BARAT \\ Ilham Nurllah, Jaya Iswari}

mengenai harga beli yang rendah di tingkat petani. Harga yang diterima para petani ini tidak memberikan insentif bagi petani untuk membudidayakan tanaman lada. Kondisinya yang berbeda dengan era tahun 1980-1990an dimana harga lada pada saat itu sangat menjanjikan dan kesejahteraan yang sangat baik kepada para petani. Dalam analisa prospek lada berdasarkan proyeksi permintaan dan penawaran akan terjadi trend permintaan sebesar 5,44\% yang terbagi atas trend konsumsi 2\% dan trend ekspor 3,44\%, sedangkan trend penawaran hanya $4,69 \%$ (Kemala, 1996). Trend permintaan yang lebih besar dari pada trend penawaran menggambarkan bahwa pada tahun-tahun yang akan datang jumlah permintaan lada akan melebihi jumlah persediaan karena konsumsi lada dunia cenderung meningkat dari tahun ke tahun. Lada (Piper nigrum L.) juga merupakan salah satu komoditi ekspor pertanian yang menjadi andalan penghasil devisa Indonesia.

Berdasarkan perilaku harga ekspor lada, diperoleh informasi bahwa pada masa tahun 1980an sampai 2000an tersebut harga lada tercatat berfluktuasi sangat tinggi, senada dengan penyampaian petani dan informasi dari para narasumber yang terkait dengan lada putih. Perilaku fluktuasi harga yang cukup tinggi ini menunjukkan tingginya dinamika yang terjadi. Jika dilihat berdasarkan harga ekspor lada setelah tahun 2010, harga lada terus merangkak naik dan mencapai puncaknya pada tahun 2015. Harga lada pada tahun 2015 tersebut memecahkan rekor dari tahuntahun sebelumnya karena mengalami lonjakan yang luar biasa. Petani menerima harga beli dari pedagang ratarata 150.000 rupiah, bahkan ada yang mencapai 170.000 rupiah untuk satu kilogram lada putih di tahun 2015 silam. Sementara harga jual ekspor berkisar antara 7-8 dolar AS per kilogram.

Bila dbandingkan antara harga ekspor lada dan produksi, secara historis harga ekspor lada kurang dari 2 dolar AS per kilogram tidak memberikan insentif bagi petani, penurunan produksi pada tingkat harga tersebut menunjukan keengganan petani untuk bertanam lada. Keengganan petani tersebut sangat beralasan karena harga lada pada titik impas menurut penuturan petani adalah 50.000 rupiah per kilogram. Hampir sama dengan analisis yang dialakukan oleh pemerintah daerah Provinsi Kepulauan Bangka Belitung dimana titik impas atau biaya produksi lada putih kering adalah 52.500 rupiah per kilogram. Harga lada 
putih di tingkat petani pada tahun 2018 berada pada kisaran 50.000 rupiah per kilogram lada kering. Impikasinya, nilai tersebut tidak memberikan insentif bagi petani karena biaya produksi lebih besar nilai yang diterima, yang berarti secara ekonomi petani tidak memperoleh keuntungan dari usaha tani lada. Harga yang diharapkan petani dan memberikan insentif apabila lada putih dibeli oleh pedagang pada kisaran 80.000-100.000 rupiah per kilogram.

Berdasarkan data dari salah satu narasumber, harga lada tertinggi terjadi pada tahun 2015 yaitu sekitar Rp
$170.000 / \mathrm{kg}$, dan harga lada terendah terjadi pada tahun 2019 yaitu sekitar Rp $51.000 / \mathrm{kg}$ nya. dapat dikatakan bahwa setiap tahun terjadi penurunan harga yang mengakibatkan terjadinya penurunan produksi dan produktivitas dari petani. Harga lada yang semakin menurun setiap tahunnya tidak diimbangi dengan biaya pupuk dan biaya perawatannya, hal ini yang menyebabkan petani lada di Kecamatan Jebus banyak yang beralih profesi, karena keuntungan dalam bertani lada tidak sebanding dengan perawatannya.

Tabel 1. Perubahan Harga Lada

\begin{tabular}{|c|c|c|c|c|c|}
\hline \multirow{2}{*}{ Keterangan } & \multicolumn{5}{|c|}{ Tahun } \\
\hline & 2015 & 2016 & 2017 & 2018 & 2019 \\
\hline Produksi/ha & $2.000 \mathrm{~kg}$ & $1.800 \mathrm{~kg}$ & $1.700 \mathrm{~kg}$ & $1.500 \mathrm{~kg}$ & $1.400 \mathrm{~kg}$ \\
\hline Harga satuan & Rp 170.000/kg & Rp 100.000/kg & $\mathrm{Rp} 60.000 / \mathrm{kg}$ & $\mathrm{Rp} 52.000 / \mathrm{kg}$ & $\mathrm{Rp} 51.000 / \mathrm{kg}$ \\
\hline Laba kotor & Rp 340.000 .000 & Rp 180.000 .000 & $\operatorname{Rp} 102.000 .000$ & $\operatorname{Rp} 78.000 .000$ & Rp 71.400 .000 \\
\hline Biaya pupuk/ha & $\mathrm{Rp} \quad 11.400 .000$ & $\mathrm{Rp} \quad 11.800 .000$ & $\mathrm{Rp} \quad 12.000 .000$ & $\operatorname{Rp} 12.500 .000$ & Rp 12.600 .000 \\
\hline Biaya umum & $\mathrm{Rp} \quad 50.000 .000$ & $\mathrm{Rp} \quad 50.000 .000$ & $\mathrm{Rp} \quad 50.000 .000$ & Rp 50.000.000 & Rp 50.000 .000 \\
\hline Laba bersih & Rp 278.000 .000 & $\mathrm{Rp} 118.200 .000$ & $\mathrm{Rp} \quad 40.000 .000$ & Rp 15.500 .000 & Rp 8.400 .000 \\
\hline
\end{tabular}

\section{KESIMPULAN DAN SARAN}

Berdasarkan uraian di atas, maka dapat ditarik kesimpulan penelitian sebagai berikut:

1. Seluruh petani mengetahui adanya perubahan harga lada yang drastis, penurunan harga yang paling drastis ini terjadi pada tahun 2015 ke 2016 yang berkisar Rp 70.000/kg, tetapi penurunan harga pada tahun tersebut masih memberikan keuntungan yang cukup besar bagi petani karena harga lada masih mencapai angka $\mathrm{Rp}$ 100.000/kg. Harga lada terendah terjadi pada tahun 2018-2019 yakni berkisar antara Rp 51.000-52.000/kg.

2. Masyarakat petani yang hanya mengandalkan sektor perkebunan tanaman lada sebagai sistem mata pencaharian utama hidupnya dihadapkan dengan permasalahan ekonomis, yaitu menurunnya harga 


\section{PENGARUH PERUBAHAN HARGA LADA PUTIH TERHADAP KESEJAHTERAAN \\ MASYARAKAT DI KECAMATAN JEBUS KABUPATEN BANGKA BARAT \\ Ilham Nurllah, Jaya Iswari}

komoditas pada sektor perkebunan tanaman lada ini secara signifikan mengakibatkan pendapatan dan tingkat kesejahteraan mereka berkurang. Jadi, wajar apabila mereka mengaku bahwa penghasilan seperti itu tidak mencukupi untuk memenuhi kebutuhan keluarganya sehari-hari.

3. Dampak yang sangat buruk terhadap kehidupan sosial ekonomi akibat dari penurunan harga lada yang drastis sangat murah, tidak diimbangi dengan harga pupuk yang sangat mahal serta masa perawatannya yang tergolong sangat sulit antara lain: menurunnya hasil panen lada karena para petani tidak lagi fokus untuk perawatan dalam mengurusi tanaman lada mereka, dan yang paling parah semakin meningkatnya jumlah petani lada untuk beralih profesi.

Berdasarkan kesimpulan penelitian, maka diajukan beberapa saran sebagai berikut:

1. Pemerintah harus lebih memperhatikan segala kebutuhan yang menjadi faktor pendukung keberhasilan masyarakat petani lada dalam meningkatkan perekonomian mereka.

2. Pemerintah harus memberikan pembinaan dan pembelajaran bagi masyarakat petani lada agar para petani mendapatkan pengetahuan serta kemampuan yang lebih untuk bersaing dan berkompetisi di pasar dunia.

3. Hendaknya pola pemasaran biji lada tidak terlalu melibatkan banyak faktor pemasaran didalamnnya, agar para petani sedikit mendapatkan hasil/pendapatan yang dapat mengurangi turunnya harga lada.

4. Untuk masyarakat petani lada perkebunannya harus tetap dijaga karena tanaman lada merupakan sebuah icon dan sebagai tanaman khas dari Kabupaten Bangka Barat dan menjadi mata pencaharian utama masyarakat Kecamatan Jebus.

\section{DAFTAR PUSTAKA}

Creswell, J.W. 2005. Research in Human Geograhy. 36(4): 475-489.

Direktorat Jenderal Bina Produksi Perkebunan.2006. Statistik Perkebunan Indonesia: Lada. Jakarta: Direktorat Jenderal Perkebunan Kementerian Perkebunan

Direktorat Jenderal Perkebunan.2014. Laporan Kinerja Direktorat Jenderal Perkebunan. Jakarta: Kementerian Pertanian

Direktorat Jenderal Perkebunan. 2015. Statistik Perkebunan Indonesia Lada Pepper 2015-2017. Jakarta: Direktorat Jenderal Perkebunan Kementrian Perkebunan 
International Pepper Community. 2004. The World Papper Industry.

Folke C. 2006. Resilience The emergence of a perspective for social ecological systems analyses. Global Environment Change 16(3): 253267.

Kemala S.1996. Strategi pengembangan sistem agribisnis lada untuk meningkatkan pendapatan petani. Pusat Penelitian dan Pengembangan Perkebunan:1-8

Kemala, S dan E. Karmawati. 2007. Keragaman Agribisnis Lada di Bangka. Prosiding Seminar Rempah. Puslitbang Perkebunan, Bogor. Hlm. 183-187.

Kotler, P. dan Keller, K.L. 2012. Marketing Management. Fourteenth Edition. Pearson International Edition. Hlm:13-14.
Mauludi, L, dan Yuhono. 1996. Tataniaga Lada di Indonesia: Monograf Tanaman Lada. Bogor: Balai Tanaman Obat dan Tropika.

Saefudin. 2014. Tantangan dan kesiapan teknologi penyediaan bahan tanam mendukung peningkatan produktivitas nasional tanaman lada (Piper nigrum L.). Perspektif. 13(2): 11-125.

Suratiyah, K .2015. Ilmu Usahatani (Edisi Revisi). Jakarta Timur: Penebar Swadaya.

Walker, Gordon. 2009. Modern Competitive Strategy Third Edition. Mc. Graw Hill International.

Yuhono, J.T .2005. Harga pokok pembuatan bibit lada. Warta Penelitian dan Pengembangan Tanaman Industri. 11: 25-2. 